\title{
Carbonización Cadavérica
}

\author{
Cadaverous Carbonization
}

Una Imagen

P. Martínez García ${ }^{1}$ y A. Sibón Olano²

La carbonización del cadáver supone un auténtico desafío para el Médico Forense. Inmediatamente surgen multitud de dudas que es urgente resolver: ¿quién es el individuo?, ¿cuál es la causa de la muerte?, ¿el sujeto vivió en el foco del incendio o fue arrojado ya cadáver?, ¿la etiología es suicida, homicida o accidental?.

Como señalaba Lecha de Marzo [1], en la autopsia de cadáveres carbonizados, nos llamará la atención la reducción de los distintos órganos del cadáver y del conjunto del cuerpo. Una cabeza de adulto puede presentar el volumen de una de niño de doce años.

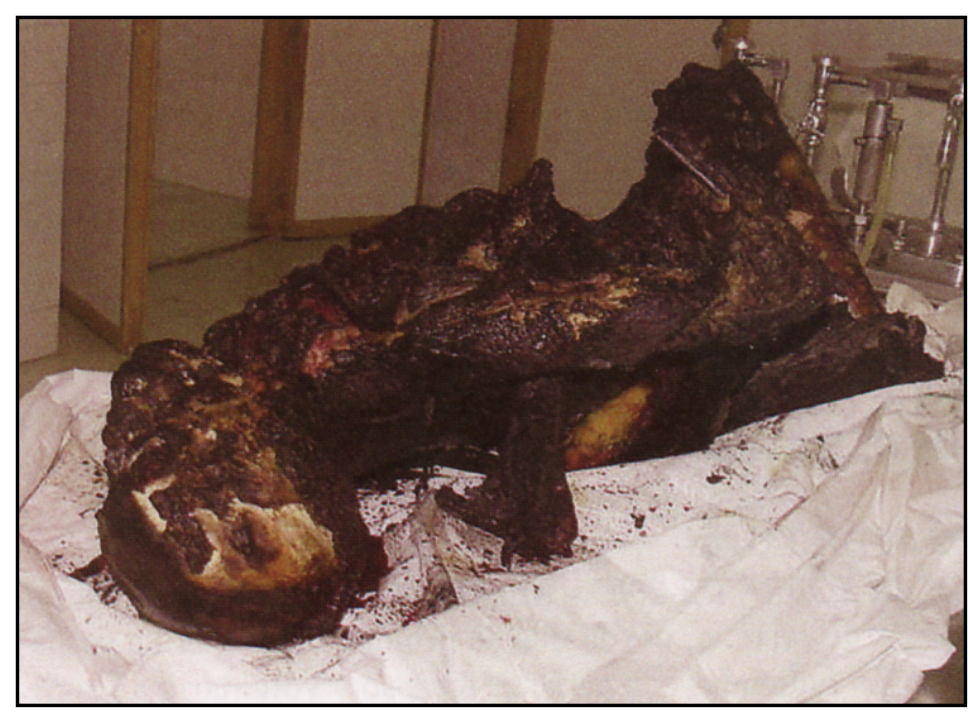

Debemos recordar también las actitudes extrañas (de lucha, de combate, de boxeo) que pueden observarse en los cadáveres carbonizados y que dependen de un fenómeno puramente físico, de la rigidez producida por el calor.

En el examen externo la piel está ennegrecida, reseca, suena como un tambor, hay soluciones de continuidad en los pliegues (que remedan heridas incisas), puede haber amputaciones espontáneas en extremidades y, si es intensa y prolongada, pueden estallar las cavidades naturales.

\footnotetext{
${ }^{1}$ Médico Forense de Cádiz.

${ }^{2}$ Médico Forense de San Fernando (Cádiz).
} 


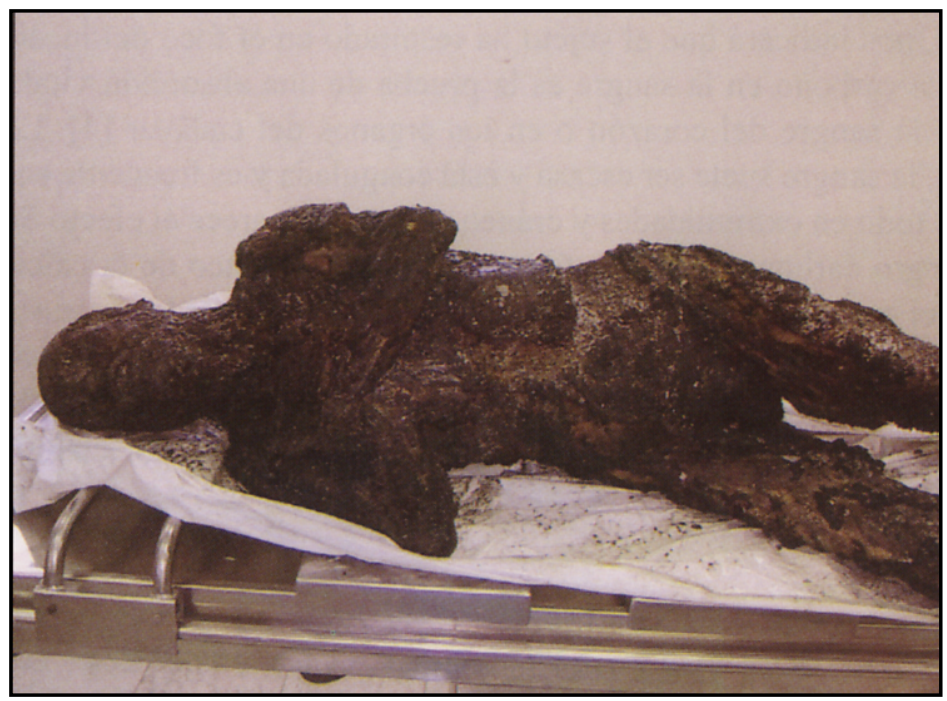

La etiología Médico-legal es fundamentalmente accidental. Hinojal y Rodríguez [2] en un estudio de 134 quemados, encuentran tan solo dos casos de suicidio y dos de homicidio.

La gran destrucción externa contrasta, en ocasiones, con la conservación de los órganos internos, que aparecen con aspecto de cocción. Solo cuando el grado de carbonización es extremo, es probable que la prueba de la agresión quede enmascarada, las quemaduras pueden borrar las pruebas de una estrangulación, por ejemplo con una bufanda, pero no tan fácilmente las fracturas o las balas [3]"

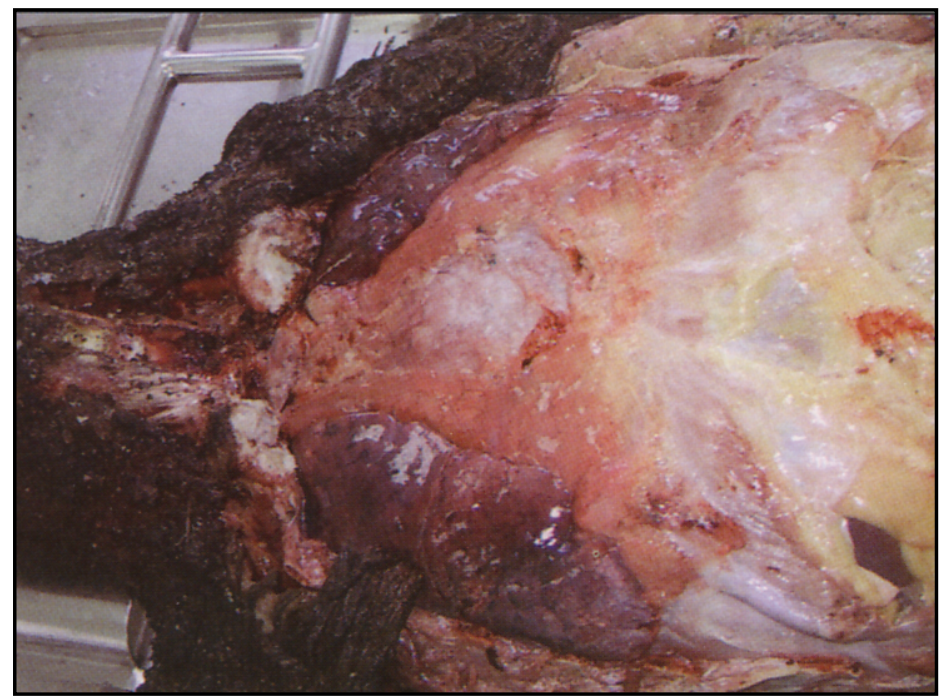


La existencia de quemaduras, hollín y material de combustión en epiglotis, laringe, tráquea y bronquios, nos indicará que el sujeto ha respirado en el foco del incendio. La presencia de óxido de carbono en la sangre es la prueba de una absorción vital: este gas no penetra nunca en la sangre del corazón o en los órganos del cadáver [4]. Los pulmones están edematosos, la sangre suele ser escasa y está coagulada y es frecuente encontrar fracturas óseas, sobre todo en extremidades y cráneo. A veces, aparece el efecto Sandwich [5], con coloración negro carbonoso en el interior del hueso y blanco de la calcinación en el exterior. Cuando el cráneo estalla, el estudio histológico de los bordes muestra la ausencia de rupturas vasculares y de infiltrado hemorrágico, así como de cualquier otro signo de vitalidad. Las meninges se retraen y puede acumularse sangre entre la duramadre y el hueso, simulando un hematoma extradural (hematoma extradural por calor, descrito por SACH).[6]"

\section{REFERENCIAS BIBLIOGRÁFICAS CONSULTADAS.-}

1.- Lecha Marzo A. Tratado de autopsias y embalsamamientos. El diagnóstico Médico Legal en el cadáver. Manuel Marín Editor. Barcelona. 1917. Capítulo XVIII. pag 404-405.

2.- Hinojal Fonseca R y Rodriguez Getino JA. Quemaduras: Estudio epidemiológico y secuelas. Revista Española de Medicina Legal. 1986; (46-47): 45-47.

3.- Simpson K.; Medicina Forense. 1981. Editorial ESPAXS S.A. pag 173-178.

4.- Simonin C: Quemaduras Comunes. En: Simonin C. Medicina Legal Judicial. Reimp 2a ed. Edit JIMS. Barcelona, 1976. pp 168-177.

5.- Subirana M, Cuquerella A, Trias E y Lucena J. Lesiones óseas por carbonización cadavérica. Cuad Med For. 2000; 22: 79 y 80 .

6.- Castellano Arroyo, M. Lesiones por agentes físicos. En: Gisbert Calabuig JA. Medicina Legal y Toxi-

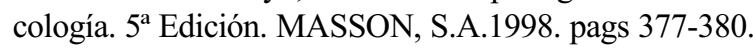

